\title{
Do shark declines create fear-released systems?
}

\author{
Alejandro Frid, Gregory G. Baker and Lawrence M. Dill \\ A. Frid (alejandro_frid@alumni.sfu.ca) and L. M. Dill, Dept. of Biological Sciences, Simon Fraser Univ., Burnaby, BC, Canada, V5A 1S6. \\ Present address for AF: 352 Creek Road, RR1 I27, Bowen Island, BC, Canada, VON 1GO-G. G. Baker, School of Computing Science, Simon \\ Fraser Univ., Burnaby, BC, Canada, V5A $1 S 6$.
}

\begin{abstract}
We illustrate the theoretical plausibility that fishery removal of sharks can indirectly alter predation pressure on different fish species via the behavioural responses of mesoconsumers released from predator intimidation. Our dynamic state variable model of foraging decisions by harbour seals, a mesopredator, predicted indirect effects of the removal of Pacific sleeper sharks on two species consumed by seals, Pacific herring and walleye pollock, as mediated by seal behaviour. Herring, a fatty fish, form near-surface aggregations that often are ephemeral and widely dispersed. Pollock are found in the deeper strata preferred by sharks and have lower energy density than herring, but also are larger and their more continuous distribution potentially makes them the more predictable resource for seals. During simulations, predation risk from sharks produced an asymmetric trophic cascade mediated by the seal's underutilisation of deeper, riskier strata. Risk management by seals reduced mortality on pollock, which required riskier access in deep strata, while increasing mortality on herring, which could be accessed with less risk in shallow strata. This effect, however, attenuated if herring were scarcer and seal energy state was poor. During shark removal scenarios, seals shifted to deeper strata, increasing pollock consumption and substantially decreasing use of herring; the proportional change was greatest if seals were in good energy state. Prior studies have addressed how shark declines might affect community structure through density responses by species consumed by sharks; earlier models incorporating antipredator behaviour of the mesopredator (i.e. Ecosim/Ecospace) allow for activity reduction but not for the spatial shifts that altered the asymmetric trophic cascade in our simulations. Our results suggest that shark declines might have stronger ecological consequences than previously recognised if we account for spatial and diet shifts by mesoconsumers released from shark intimidation.
\end{abstract}

Fishery exploitation threatens shark species almost worldwide (Baum et al. 2003, Clarke et al. 2006). Given that large-bodied sharks are top predators, their removal can influence community structure via density increases in mesoconsumers (Shepherd and Myers 2005). Ensuing disruptions to trophic cascades may cause the decline or extinction of species at lower trophic levels. For instance, correlative analyses suggest that declines of large sharks in the northwest Atlantic indirectly collapsed bay scallop populations via increases in mesopredatory elasmobranchs (Myers et al. 2007). Other studies report similar densitymediated indirect interactions (DMII: Abrams 1995) initiated by the loss of upper level predators in marine (Scheffer et al. 2005) and terrestrial systems (Berger et al. 2001, Johnson et al. 2007). Yet DMIIs are an incomplete portrayal of how the loss of top predators might disrupt ecological communities.

Consider trait-mediated indirect interactions (TMII: Abrams 1995), whereby one species inducing a behavioural or morphological response by a second species influences the fitness of a third through effects transmitted (or mediated) by the second species (Werner and Peacor 2003). For instance, mesoconsumers may optimise tradeoffs between energy gain and predation risk by underutilising resources associated with greater danger, and instead selecting less profitable resources that can be accessed more safely (Lima and Dill 1990, Brown and Kotler 2004). Consequently, the risk-management decisions of mesoconsumers may mediate asymmetric trophic cascades in which predator intimidation indirectly decreases the mortality rates of some species at lower trophic levels (resource species) while simultaneously increasing the mortality rate of other resource species (Werner and Peacor 2003, Schmitz et al. 2004, Fortin et al. 2005). In turn, predator removals can reverse asymmetric trophic cascades if mesoconsumers respond to the release from fear by switching their foraging effort to the more profitable resource species (Schmitz 2003, Schmitz et al. 2004).

The strength of these indirect interactions might depend on the energy state of mesoconsumers. The foraging opportunity cost of antipredator behaviour is less affordable to individuals in poor energy state, who risk imminent starvation or other net loss of reproductive potential, and for whom it may be optimal to take greater risks (McNamara and Houston 1987, Clark 1994, Anholt and Werner 1995, Sinclair and Arcese 1995). Consequently, resource scarcity and poor energy state may combine synergistically to weaken and strengthen, respectively, the 
influence of TMIIs and DMIIs on trophic cascades (Luttbeg et al. 2003). Clearly, TMII models that consider state-dependent decisions by mesoconsumers should be powerful tools for predicting the indirect effects of shark declines on lower trophic levels.

From this theoretical backdrop, we asked whether shark declines create fear-released systems that behave differently from fear-driven systems. Does the presence and absence of shark intimidation indirectly influence relative predation pressure on different fish species via the risk-management decisions of individual mesoconsumers? Does the magnitude of these indirect interactions depend on the energy reserves and resource levels experienced by individual mesoconsumers?

Dynamic state variable models (Clark and Mangel 2000) match our objectives because they explicitly incorporate the effect of energy reserves and resource level into optimal riskmanagement decisions. They can also consider oxygen level as a state that influences optimal diving behaviour by aquatic foragers that breathe air. Accordingly, we developed a dynamic state variable model of foraging decisions made under predation risk by an air-breathing mesopredator, the harbour seal Phoca vitulina richardsi, in Prince William Sound (PWS), Alaska. We used the model to predict how optimal risk-management decisions made by individual seals might mediate the indirect effect of Pacific sleeper sharks Somniosus pacificus, a deep-water top predator (Sigler et al. 2006, Hulbert et al. 2006), on two species of fish consumed by seals, Pacific herring Clupea pallasi and walleye pollock Theragra chalcogramma. Herring, a fatty fish, forms near-surface aggregations that often are ephemeral and widely dispersed (Thomas and Thorne 2001, 2003). Pollock are found in the same deeper strata preferred by sharks and have lower energy density than herring (Thorne 2004, Trumble et al. 2003), but also are larger and their more continuous distribution potentially makes them the more predictable resource for seals (Frid et al. 2007a). Mammaleating killer whales Orcinus orca are a well-recognized predator of seals at or near the surface, but declined from 22 to 11 individuals in PWS between 1989 and 2002 (Matkin et al. 2003). Thus, relative danger from killer whales may currently be lower than in previous decades.

Our choice of model system was motivated by prior analysis of individual variation in seal foraging tactics, which suggested that PWS seals perceive sleeper sharks to be dangerous (Frid et al. 2007a). This groundwork, which allowed us to develop a general approach that can be applied to other systems with substantiated shark declines, is summarised as follows. Frid et al. (2007a) began with the key assumption that behavioural plasticity reflects 'hazardous duty pay': foraging individuals choosing to incur higher risk of predation should experience higher energetic gain than individuals choosing safer foraging options (Brown and Kotler 2004). Next, they predicted net energy gain and predation risk per foraging dive, parameterising an analytical model with field data on seal behaviour, resource distributions and use of the water column by sharks and killer whales. This was followed by computer experiments which sought the level of relative danger from sharks and killer whales, as depicted by two parameters, required to generate the pattern of individual variability in risk-taking and energy gain that best conformed to the assumption of 'hazardous duty pay'. The results suggested that shark intimidation exerted a much stronger nonlethal effect on seals than that caused by killer whales, causing some individual seals to under-utilise resources in deep strata to reduce risk from sharks (Frid et al. 2007a).

Our present study contrasts simulations in which individual seals optimise tradeoffs between energy gain and predation risk in the presence and absence of Pacific sleeper sharks. Given that fisheries remove sharks and resources consumed by mesopredators, we also considered how TMIIs are affected by behavioural responses to the synergy of predation risk, resource availability and the individual's energetic state. Accordingly, shark risk scenarios were combined factorially with different levels of resource abundance and of the initial energy state of seals. Our results suggest that, although resource levels and energy state might modulate the strength of TMIIs, the ecological impacts of shark declines might be stronger than previously thought when we consider spatial shifts and prey-switching by mesoconsumers released from predator intimidation.

\section{Methods}

\section{Model derivation}

The dynamic state variable model presented here is modified from Frid et al. (2006) and is specific to adult females. While seals might prey on several fish species, the model considers only Pacific herring and walleye pollock. This simplification is justified because both species appear to be top prey items for seals at our study site (Iverson et al. 1997). In addition, empirical data required for parameterisation were available for only these two species.

Inherent to the model are decisions made by individual seals at the scale of a dive cycle - time uploading oxygen at the surface, travelling the water column, and foraging at a resource patch - which could influence tradeoffs between energy gain and predation risk (Heithaus and Frid 2003, Frid et al. 2006, 2007a, 2007b). The model accommodates diving behaviour by dividing the time-span preceding the terminal horizon, $\mathrm{T}$, into 20 -s periods, $\mathrm{t}$, when decisions are made (i.e. 103680 t). Decisions consist of either staying at the current location or initiating a move towards a future location. Moves occur at a rate of $1 \mathrm{~m} \mathrm{~s}^{-1}$. They are either horizontal, if moving between a haulout and the surface of a foraging habitat located $1.5 \mathrm{~km}$ offshore, or vertical, if diving between the surface and a shallow, mid-depth or deep resource patch, with respective depths of 20,60 and $140 \mathrm{~m}$. Density dependence (e.g. intraspecific competition and risk dilution) could not be included in the model because the increased computational complexity would have undermined our objective of modeling decisions on a perdive basis.

Each simulation represents a 23-day period, the maximum duration allowed by computer memory, in which the behaviour of seals has already adapted to a given set of conditions. Though arguably short, these $23-\mathrm{d}$ time slices are ecologically relevant. Their parameterisation reflects late winter, when important seasonal resources, including eulachon Thaleichthys pacificus and salmon Oncorhynchus sp., are unavailable at shallow strata and seals are more likely 
to forage deep and overlap spatially with sharks. Further, data on the depth distribution of fish along the foraging tracks of seals, which were essential to parameterisation, were available only for a late winter period of almost equal length and timing (Frid et al. 2007a) as that covered by the model.

There are two internal state variables: $\mathrm{X}(\mathrm{t})=\mathrm{x}$ represents energy reserves at $t$ and $Y(t)=y$ represents oxygen stores at t. For $\mathrm{X}(\mathrm{t})$, we assumed an energy density of $15.9 \mathrm{MJ} \mathrm{kg}^{-1}$ (Bowen et al. 2001) and that body weights ranged from 50 to $85 \mathrm{~kg}$, such that $\mathrm{x}_{\min }=796.2 \mathrm{MJ}$ and $\mathrm{x}_{\max }=1353.5 \mathrm{MJ}$. From the range $x_{\max }-x_{\min }=557.3 \mathrm{MJ}$ and Eq. 2.3 of Clark and Mangel (2000), we created 46 discretized computer values of $\mathrm{X}(\mathrm{t}): 0$ to 45 , with 0 implying death by starvation. For $Y(t)$, we assumed that, depending on the stage of the dive, 105.11-121.27 $\mathrm{ml}$ of oxygen are consumed per 20-s time period spent diving (Davis et al. 1985, Table 1), and that oxygen level can rise from $y_{\min }=0$ to $y_{\max }=3322.21 \mathrm{ml}$ during a $120 \mathrm{~s}$ surface interval. Thus, $y_{\max }$ allows dive durations of $640 \mathrm{~s}$. From the range $y_{\max }-$ $\mathrm{y}_{\min }=3322.21 \mathrm{ml}$ and Eq. 2.3 of Clark and Mangel (2000), we created 11 discretized computer values (0-10) of $Y(t)$. The oxygen gain function in Eq. 1 (see below) was constructed so that the resulting surface and dive durations were consistent with the range recorded during preliminary field observations (Frid unpubl.). Table 1 lists parameter values for energy and oxygen costs associated with each activity

At the onset of simulations, seals are at the haulout, which provides refuge from predators but no food. Foraging trips are initiated by traveling horizontally for 75 time periods to the surface of the foraging habitat (hereafter, 'surface'); the return trip requires an equal amount of time. The surface has no food, but is where oxygen is uploaded for diving; seals must be there before descending to a resource patch. Descent to the shallow, mid-depth, and deep resource patches require 1,3 and 7 time periods, respectively; ascents to the surface require an equal amount of time. Seals can visit only one resource patch per dive, and must return to the surface before travelling horizontally to the haulout.

The five locations are represented by an environmental state, $\mathrm{H}(\mathrm{t})=\mathrm{h}$. The values of $\mathrm{h}$ correspond to the number of 20-s time periods required for one-way travel to that location from the haulout or, in the case of resource patches, from the surface. Thus, the haulout and the surface are represented by $\mathrm{H}(\mathrm{t})=0$ and $\mathrm{H}(\mathrm{t})=75$, respectively. The shallow, mid-depth and deep resource patches, are represented by $\mathrm{H}(\mathrm{t})=1, \mathrm{H}(\mathrm{t})=3$ and $\mathrm{H}(\mathrm{t})=7$, respectively.

The decision variable is $\mathrm{D}(\mathrm{x}, \mathrm{y}, \mathrm{h}, \mathrm{t})=\mathrm{d}$, where $\mathrm{d}$ is the future location (i.e. one of the five values of $h$ ) chosen by a seal from its current location $\mathrm{h}$. The transition from $\mathrm{h}$ to $\mathrm{d}$ is completed at either $\mathrm{t}+1$ if not switching habitats (i.e. $\mathrm{d}=\mathrm{h}$ ) or at $\mathrm{t}+$ time $(\mathrm{h}, \mathrm{d})$ if switching habitats (i.e. $\mathrm{d} \neq \mathrm{h}$ ), where time $(\mathrm{h}, \mathrm{d})$ is number of 20 -s periods required to switch locations.

Next, we describe how decisions affect state variables at the subsequent time period. A seal at the haulout or at the surface can decide to remain or switch habitats. If it stays at the current habitat, $\mathrm{D}(\mathrm{x}, \mathrm{y}, \mathrm{h}, \mathrm{t})=\mathrm{d}$, with $\mathrm{h}=\mathrm{d}$ and

$$
\begin{aligned}
\mathrm{X}(\mathrm{t}+1)= & \mathrm{x}-\alpha_{\mathrm{h}, \mathrm{d}} \\
\mathrm{Y}(\mathrm{t}+1)= & \left\{\begin{array}{cc}
\mathrm{y}_{\mathrm{k}} & \text { if } \mathrm{h}=0 \\
\mathrm{y}+\beta \mathrm{e}^{-z y} & \text { if } \mathrm{h}=75
\end{array}\right. \\
\mathrm{H}(\mathrm{t}+1)= & \mathrm{d} \\
\operatorname{Pr}\{\mathrm{h}, \mathrm{d}\}= & 1-\mu_{\text {shark }}(\mathrm{h}, \mathrm{d})-\mu_{\text {orca }}(\mathrm{h}, \mathrm{d}) \\
& +\mu_{\text {shark }}(\mathrm{h}, \mathrm{d}) \mu_{\text {orca }}(\mathrm{h}, \mathrm{d})
\end{aligned}
$$

where $\alpha_{\mathrm{h}, \mathrm{d}}$ is the energetic cost of decision $\mathrm{d}$ made at location $h$; the constant $y_{k}=6$ represents oxygen stores when not diving (i.e. at the haulout or during surface transit); parameters $\beta=1693$ and $\mathrm{z}=0.0007$ determine the shape of the oxygen gain curve as a decelerating function of $\mathrm{Y}(\mathrm{t})=\mathrm{y}$ (Kramer 1988). The notation $\operatorname{Pr}\{\mathrm{h}, \mathrm{d}\}$ indicates the probability of surviving the transition from $h$ to $d$, where $\mu_{\text {shark }}(\mathrm{h}, \mathrm{d})$ and $\mu_{\text {orca }}(\mathrm{h}, \mathrm{d})$ are the probabilities of predation by sleeper sharks and killer whales, respectively, when making decision $\mathrm{d}$ at $\mathrm{h}$.

If a seal decides to move between the haulout and the foraging habitat, $\mathrm{D}(\mathrm{x}, \mathrm{y}, \mathrm{h}, \mathrm{t})=\mathrm{d}$, with $(\mathrm{h}, \mathrm{d})$ one of $(0,75)$ or $(75,0)$, and

$$
\begin{aligned}
& \mathrm{X}(\mathrm{t}+\operatorname{time}(\mathrm{h}, \mathrm{d}))=\mathrm{x}-\operatorname{time}(\mathrm{h}, \mathrm{d}) \alpha_{\mathrm{h}, \mathrm{d}} \\
& \mathrm{Y}(\mathrm{t}+\operatorname{time}(\mathrm{h}, \mathrm{d}))=\mathrm{y}_{\mathrm{k}} \\
& \mathrm{H}(\mathrm{t}+\operatorname{time}(\mathrm{h}, \mathrm{d}))=\mathrm{d} \\
& \operatorname{Pr}\{\mathrm{h}, \mathrm{d}\}=\left(1-\mu_{\text {shark }}(\mathrm{h}, \mathrm{d})-\mu_{\text {orca }}(\mathrm{h}, \mathrm{d})\right. \\
& \quad+\mu_{\text {shark }}(\mathrm{h}, \mathrm{d}) \mu_{\text {orca }}(\mathrm{h}, \mathrm{d}){ }^{\text {time(h,d })}
\end{aligned}
$$

If a seal at the surface dives, or a seal at a foraging patch ascends, $\mathrm{D}(\mathrm{x}, \mathrm{y}, \mathrm{h}, \mathrm{t})=\mathrm{d}$, with $(\mathrm{h}, \mathrm{d})$ one of $(75,1),(1,75)$, $(75,3),(3,75),(75,7)$, or $(7,75)$ and

$$
\begin{aligned}
& \mathrm{X}(\mathrm{t}+\operatorname{time}(\mathrm{h}, \mathrm{d}))=\mathrm{x}-\operatorname{time}(\mathrm{h}, \mathrm{d}) \alpha_{\mathrm{h}, \mathrm{d}} \\
& \mathrm{Y}(\mathrm{t}+\operatorname{time}(\mathrm{h}, \mathrm{d}))=\mathrm{y}-\operatorname{time}(\mathrm{h}, \mathrm{d}) \mathrm{u}_{\mathrm{h}, \mathrm{d}} \\
& \mathrm{H}(\mathrm{t}+\operatorname{time}(\mathrm{h}, \mathrm{d}))=\mathrm{d} \\
& \operatorname{Pr}\{\mathrm{h}, \mathrm{d}\}=\left(1-\mu_{\text {shark }}(\mathrm{h}, \mathrm{d})-\mu_{\text {orca }}(\mathrm{h}, \mathrm{d})\right. \\
& +\mu_{\text {shark }}(\mathrm{h}, \mathrm{d}) \mu_{\text {orca }}(\mathrm{h}, \mathrm{d})^{\text {time(h,d })}
\end{aligned}
$$

where $u_{h, d}$ is the oxygen cost of decision $d$ at location $h$.

When a seal at a foraging patch $(h=1,3,7)$ chooses to remain there $(h=d)$, there are two possible outcomes. First, the seal may encounter and capture prey with probability $\lambda_{\mathrm{h}, \mathrm{d}}$ and then

Table 1. Energy and oxygen costs of activity per 20-s time period.

\begin{tabular}{lcccc}
\hline Description of activity & Location $\mathrm{H}(\mathrm{t})=\mathrm{h}$ & Decision $\mathrm{D}(\mathrm{x}, \mathrm{y}, \mathrm{h}, \mathrm{t})=\mathrm{d}$ & Energetic cost $(\mathrm{kJ}) \alpha_{\mathrm{h}, \mathrm{d}}$ & Oxygen cost $(\mathrm{ml}) \mathrm{u}_{\mathrm{h}, \mathrm{d}}$ \\
\hline Remain at refuge or surface & 0,75 & $\mathrm{~d}=\mathrm{h}$ & 1.94 & - \\
Travel at surface & 0,75 & $\mathrm{~d} \neq \mathrm{h}, 1,3$, or 7 & 3.25 & - \\
Travel between surface and depth & $75,1,3,7$ & $\mathrm{~d} \neq \mathrm{h}$ or 0 & 2.11 & 105.11 \\
Resource search at depth & $1,3,7$ & $\mathrm{~d}=\mathrm{h}$ & 2.44 & 121.27 \\
\hline
\end{tabular}

Notes: energetic costs were calculated from oxygen consumption during surface travel at $1 \mathrm{~m} \mathrm{~s}^{-1}$ and during resting at the surface by a $63 \mathrm{~kg}$ harbor seal (Davis et al. 1985) using standard conversion factors. However, data on oxygen consumption were unavailable for travel between and resource search within a depth stratum, and these activities were assumed to be $65 \%$ and $75 \%$ as costly as surface swimming (Williams et al. 2000). Similarly, energetic cost of remaining at the haulout was assumed to equal that of resting at the surface. 


$$
\begin{aligned}
\mathrm{X}(\mathrm{t}+1)= & \mathrm{x}+\mathrm{g}_{\mathrm{hd}}-\mathrm{c} \alpha_{\mathrm{h}, \mathrm{d}} \\
\mathrm{Y}(\mathrm{t}+1)= & \mathrm{y}-\mathrm{cu}_{\mathrm{h}, \mathrm{d}} \\
\mathrm{H}(\mathrm{t}+1)= & \mathrm{d} \\
\operatorname{Pr}\{\mathrm{h}, \mathrm{d}\}= & 1-\mu_{\text {shark }}(\mathrm{h}, \mathrm{d})-\mu_{\text {orca }}(\mathrm{h}, \mathrm{d}) \\
& +\mu_{\text {shark }}(\mathrm{h}, \mathrm{d}) \mu_{\text {orca }}(\mathrm{h}, \mathrm{d})
\end{aligned}
$$

where $g_{h, d}$ is energy gain at $h$ if prey are captured and parameter $\mathrm{c}=2$ represents the added cost of chasing and handling prey.

If the seal does not encounter prey, with probability $1-\lambda_{\mathrm{h}, \mathrm{d}}$, then

$$
\begin{aligned}
\mathrm{X}(\mathrm{t}+1)= & \mathrm{x}-\alpha_{\mathrm{h}, \mathrm{d}} \\
\mathrm{Y}(\mathrm{t}+1)= & \mathrm{y}-\mathrm{u}_{\mathrm{h}, \mathrm{d}} \\
\mathrm{H}(\mathrm{t}+1)= & \mathrm{d} \\
\operatorname{Pr}\{\mathrm{h}, \mathrm{d}\}= & 1-\mu_{\text {shark }}(\mathrm{h}, \mathrm{d})-\mu_{\text {orca }}(\mathrm{h}, \mathrm{d}) \\
& +\mu_{\text {shark }}(\mathrm{h}, \mathrm{d}) \mu_{\text {orca }}(\mathrm{h}, \mathrm{d})
\end{aligned}
$$

Let $\mathrm{F}(\mathrm{x}, \mathrm{y}, \mathrm{h}, \mathrm{t})$ be the maximum expected reproductive success at $T$, given that $X(t)=x, Y(t)=y, H(t)=h$, and the animal behaves optimally from $t+1$ until $T$. Let $V_{d}(x, y, h, t)$ be the fitness value of decision $\mathrm{d}$, as determined by Eq. 1-5, for a given time period and set of states. Then, the dynamic programming equations (Clark and Mangel 2000) are:

$$
\begin{aligned}
& F(x, y, 0, t)=\max \left\{V_{0}(x, y, 0, t), V_{75}(x, y, 0, t)\right\} \\
& F(x, y, 75, t)=\max \left\{V_{0}(x, y, 75, t), V_{75}(x, y, 75, t),\right. \\
& \left.V_{1}(x, y, 75, t), V_{3}(x, y, 75, t), V_{7}(x, y, 75, t)\right\} \\
& F(x, y, 1, t)=\max \left\{V_{1}(x, y, 1, t), V_{75}(x, y, 1, t)\right\} \\
& F(x, y, 3, t)=\max \left\{V_{3}(x, y, 3, t), V_{75}(x, y, 3, t)\right\} \\
& F(x, y, 7, t)=\max \left\{V_{7}(x, y, 7, t), V_{75}(x, y, 7, t)\right\}
\end{aligned}
$$

After $\mathrm{T}$, adult females have two months to further build the energy reserves that will partly fuel lactation (Bowen et al. 2001). Thus, we assumed the following terminal fitness function, which decelerates smoothly (see Appendix 1 for sensitivity analyses):

$\mathrm{F}(\mathrm{x}, \mathrm{y}, \mathrm{h}, \mathrm{T})=1-\left(1-\left(\mathrm{x} / \mathrm{x}_{\max }\right)\right)^{3.25}$

We solved Eq. set 6 through backward iteration (Clark and Mangel 2000) from Eq. 7.

\section{Baseline parameterisation for resources and predation risk}

The probability of encountering and capturing a fish per 20-s time period spent at $\mathrm{H}(\mathrm{t})=\mathrm{h}, \lambda_{\mathrm{h}, \mathrm{d}}$, was estimated as: $\lambda_{\mathrm{h}, \mathrm{d}}=\varphi \mathrm{P}_{\mathrm{s}, \delta}$

where $\mathrm{P}_{s, \delta}$ is the expected number of fish encountered and caught $(\mathrm{a}$ number $<1$ ) during the first second spent at depth $s$ during diel period $\delta$ (Frid et al. 2007a). The values of $\mathrm{P}_{\mathrm{s}, \delta}$ for $\mathrm{H}(\mathrm{t})=1, \mathrm{H}(\mathrm{t})=3$, and $\mathrm{H}(\mathrm{t})=7$ were calculated, respectively, as the means of 10-m depth intervals for the depth ranges 5-55 m, 55-95 m, and 95-205 m (Appendix 2 ). The constant $\varphi=1.8$ scales energy gain per 20 -s periods to a realistic rate, as determined through preliminary simulations. Table 2 lists values of $\lambda_{\mathrm{h}, \mathrm{d}}$.

Although our interest is on shark intimidation, killer whales predation occurs in the system (Saulitis et al. 2000) and we include a background level of killer whale predation risk. Let $T_{i, s, \delta}$ be the proportions of time spent by predator $i$ (killer whale or shark) at s during $\delta$ (Frid et al. 2007a). The values of $T_{i, s, \delta}$ for $H(t)=1, H(t)=3$, and $H(t)=7$ were calculated, respectively, as the means of $10-\mathrm{m}$ depth intervals for the depth ranges 5-55 $\mathrm{m}, 55-95 \mathrm{~m}$ and 95$205 \mathrm{~m}$ (Appendix 2). Thus, $\mu \mathrm{i}(\mathrm{h}, \mathrm{d})$, the probability of predation by predator $\mathrm{i}$ at $\mathrm{H}(\mathrm{t})=\mathrm{h}$ during $\delta$, is:

$\mu_{\mathrm{i}}(\mathrm{h}, \mathrm{d})=\rho \omega_{\mathrm{i}} \mathrm{T}_{\mathrm{i}, \mathrm{s}, \delta}$

where $\omega_{\mathrm{i}}$ represents relative danger from each predator type, such that $\omega_{\text {shark }}=3.75 \times 10^{-9}$ and $\omega_{\text {orca }}=5.00 \times 10^{-9}$ (Frid et al. 2007a). The constant $\rho=40.0$ scales predation risk to realistic levels, as determined by preliminary simulations. Table 2 lists values of $\mu_{\mathrm{i}}(\mathrm{h}, \mathrm{d})$.

Only one fish is caught per successful time period at a foraging patch. We assume that 122-g Pacific herring and 424-g walleye pollock are the only resources at $\mathrm{H}(\mathrm{t})=1$ and $\mathrm{H}(\mathrm{t})=7$, respectively (Frid et al. 2007a). At $\mathrm{H}(\mathrm{t})=3$ we assume that herring and pollock of these sizes are found in equal proportions. Based on energy densities during spring

\begin{tabular}{|c|c|c|c|c|c|c|}
\hline \multirow[t]{2}{*}{ *Location } & \multicolumn{2}{|c|}{$\begin{array}{l}\text { Probability of obtaining a } \\
\text { resource } \lambda_{\mathrm{h}, \mathrm{d}}\end{array}$} & \multicolumn{2}{|c|}{$\begin{array}{c}{ }^{\S_{\text {Killer }} \text { whale predation }} \\
\text { probability } \mu_{\text {orca }}(\mathrm{h}, \mathrm{d})\end{array}$} & \multicolumn{2}{|c|}{$\begin{array}{l}{ }^{\S} \text { Sleeper shark predation } \\
\text { probability } \mu_{\text {shark }}(\mathrm{h}, \mathrm{d})\end{array}$} \\
\hline & Day & Night & Day & Night & Day & Night \\
\hline Haulout & 0 & 0 & 0 & 0 & 0 & 0 \\
\hline Surface & 0 & 0 & $2.00 \times 10^{-7}$ & $2.00 \times 10^{-7}$ & 0 & 0 \\
\hline 20-m depth & $2.32 \times 10^{-3}$ & $5.12 \times 10^{-3}$ & $3.77 \times 10^{-8}$ & $3.88 \times 10^{-8}$ & $8.65 \times 10^{-9}$ & $6.17 \times 10^{-8}$ \\
\hline 60-m depth & $4.20 \times 10^{-3}$ & $5.60 \times 10^{-3}$ & $2.04 \times 10^{-9}$ & $1.49 \times 10^{-9}$ & $2.10 \times 10^{-7}$ & $2.51 \times 10^{-7}$ \\
\hline 140-m depth & $8.15 \times 10^{-3}$ & $8.19 \times 10^{-3}$ & $1.24 \times 10^{-10}$ & $1.98 \times 10^{-11}$ & $7.15 \times 10^{-7}$ & $8.23 \times 10^{-7}$ \\
\hline
\end{tabular}
for herring $\left(5.80 \mathrm{~kJ} \mathrm{~g}^{-1}\right.$ : Paul et al. 1998) and during March for adult pollock (4.08 $\mathrm{kJ} \mathrm{g}^{-1}$ : Vollenweider 2004), and an assumed assimilation efficiency of 0.9 (Rosen et al. 2000), gross energy gain per fish captured, $\mathrm{g}_{\mathrm{h}, \mathrm{d}}$, is $634.60 \mathrm{~kJ}$ at $\mathrm{H}(\mathrm{t})=1,1095.73 \mathrm{~kJ}$ at $\mathrm{H}(\mathrm{t})=3$, and $1556.86 \mathrm{~kJ}$ at $\mathrm{H}(\mathrm{t})=7$.

To account for diel changes in predation risk and resource encounter probabilities (Table 2), we assume durations of 13 and $11 \mathrm{~h}$ for day and night day, respectively (based on sunrise and sunset times for Cordova, Alaska, during $10 \mathrm{March}$, the midpoint of the simulation period). Thus, let day_len $=4320$, the number of 20-s time periods $\mathrm{t}$ in a day. Daytime parameter values

Table 2. Probabilities of encountering resources and of being killed by predation per 20-s period spent at a each location (i.e. if $\mathrm{D}(\mathrm{x}, \mathrm{y}, \mathrm{h}$, $\mathrm{t})=\mathrm{h}$.

*the mathematical designations of each location are, from top to bottom, $\mathrm{H}(\mathrm{t})=0,75,1,3,7$.

$\S$ if $D(x, y, h, t) \neq h$, predation probabilities were multiplied by 0.50 for surface travel and by 0.25 for travel between the surface and foraging patches. The rationale is that movement between foraging locations might reduce predation risk (Mitchell and Lima 2002), and a seal at the surface might be more able to monitor the approach of killer whales. 
are used if (day_len $-\mathrm{t}([\bmod ]$ day_len $)) \geq \frac{13}{24}$ day_len, otherwise night-time values are used. Although the model accounts for diel changes in risk-energy tradeoffs, for brevity we report only overall responses.

\section{Computer experiments}

Solution to the dynamic programming equation generates an optimal decision matrix for all combinations of state variables and time periods. Based on this matrix, we used forward iterations (Clark and Mangel 2000) to conduct computer experiments in which herring and pollock were either scarce or abundant. The resource levels used for these treatments were proportional to the maximum and minimum yearly biomass estimates made during 1995-2003, the time series available for both fish species in PWS (Thomas and Thorne 2003, Thorne 2004).

As noted earlier, baseline parameter values (Table 2) derive from data collected in 2004 (Frid et al. 2007a). That year, the estimated herring biomass was 24800 t (R. E. Thorne unpubl.). Equivalent data are lacking for pollock, and we assumed a 2004 pollock biomass of $25100 \mathrm{t}$, which is the mean (SD $\pm 2425 \mathrm{t}$ ) for 2001-2003 (Thorne 2004). During the available time series, pollock biomass peaked at $38700 \mathrm{t}$ in 1997 and dipped to $22300 \mathrm{t}$ in 2003. These estimates are, respectively, 1.54 and 0.89 times the assumed biomass for 2004; baseline values of $\lambda_{7, d}$ (Table 2) were multiplied by these proportional changes to parameterize abundant and scarce levels of pollock. Similarly, estimated herring biomass peaked at $38000 \mathrm{t}$ during 1997 and dipped to $6700 \mathrm{t}$ during 2001 . These estimates are, respectively, 1.53 and 0.27 times the 2004 herring biomass, and $\lambda_{1, \mathrm{~d}}$ baseline values (Table 2 ) were multiplied by these proportional changes to parameterize abundant and scarce levels of herring. For a given treatment, the $\lambda_{3, \mathrm{~d}}$ baseline value (Table 2) was multiplied by the mean of the proportional changes to $\lambda_{1, \mathrm{~d}}$ and $\lambda_{7, \mathrm{~d}}$ values. Throughout, we assumed that the depth distribution of resource and predator species and that relative danger from sharks and killer whales remained unchanged from the 2004 estimates (Frid et al. 2007a).

Both levels of herring and pollock abundance were combined factorially with good and poor levels of the seal's initial energy state ( $90 \%$ and $50 \%$ of maximum, respectively) and with two levels of shark risk (sharks present or absent), while maintaining predation risk from killer whales constant at a low background level (Table 2). Each of the 16 treatment combinations was replicated 1000 times, and we report predicted behaviours as the mean outcome of each treatment combination. Results, however, include only replicates in which individuals survived to $\mathrm{T}$, and thus are analogous to results from risk manipulations of empirical studies in which deactivated predators threaten but cannot kill (Schmitz et al. 2004). (Depending on initial energy state and resource levels, 'mortalities' due to predation occurred in $0.5-4.0 \%$ of simulations that included shark risk. Given our focus on nonlethal effects, these mortalities are not discussed further.)

We quantified the indirect of sharks on fish that was mediated by seal behaviour (TMII) as the proportional difference in predation by seals on fish when sharks were present relative to when sharks were absent. Based on Luttbeg et al. (2003),
TMII $=\frac{\text { fish eaten }(\text { shark risk manipulation })}{\text { fish eaten }(\text { no shark manipulation })}-1$

where fish eaten is the mean number of fish eaten by individual seals during the 23-d simulation period under the given manipulation. The shark risk manipulation consisted of simulations in which mortality risk per time period from both sharks and killer whales was present (recall that background risk from killer whales is much lower than that from sharks: Table 2), but included only replicates in which seals survived to $\mathrm{T}$ (i.e. fish eaten $=$ sum of fish eaten by non-depredated seals/number of seals not killed by either predator). The no shark manipulation consisted of simulations in which shark risk was removed but risk from killer whales was maintained, and excluded the few replicates $(0-0.1 \%$ per treatment combination) in which killer whale predation occurred (i.e. fish eaten $=$ sum of fish eaten by non-depredated seals/number of seals not depredated by killer whales).

\section{Results}

\section{The transmission mechanism}

The main transmission mechanism of indirect effects of sharks on fish - number of dives by seals to each stratum depended on interactions between multiple factors. If initial energy state was good, sharks present, and herring abundant, few dives were deep $(<1 \%)$, most were shallow (66$76 \%$, depending on pollock abundance), and the remainder were to mid-depth (Fig. 1a). Under these conditions pollock abundance had little effect on depth choice, but a change from scarce to abundant pollock caused an $18 \%$ decline in the total number of dives (Fig. 1a).

If initial energy state was poor, sharks present, herring abundant, and pollock scarce, most dives (71\%) were to mid-depth, and the remainder were approximately evenly distributed between deep (17\%) and shallow strata (12\%) (Fig. 1b). Under these conditions, a change from scarce to abundant pollock caused a $16 \%$ decline in the total number of dives, an increase in the proportion of mid-depth dives ( $86 \%$ of total dives), and fewer deep dives ( $4 \%$ of total) (Fig. 1b).

If herring were scarce, almost all dives were deep, regardless of other factors (a few dives were to mid-depth: Fig. $1 \mathrm{c}-\mathrm{d}$ ). Under these conditions, a change from scarce to abundant pollock decreased the total number of dives by $40-46 \%$, depending on energy state and shark treatment (Fig. 1c-d).

Removal of sharks led to almost exclusive use of deep strata. The exceptions were when herring were abundant and pollock scarce, in which case dives were approximately evenly distributed between mid-depth and deep strata, regardless of initial energy state (Fig. 1c-d). When herring were scarce, the removal of sharks led to a much greater increase in the number of deep dives if initial energy state was good rather than poor, and the difference was amplified if pollock were abundant (Fig. 1).

For all treatment combinations, the total number of dives was greater if initial energy state was poor (Fig. 1). 

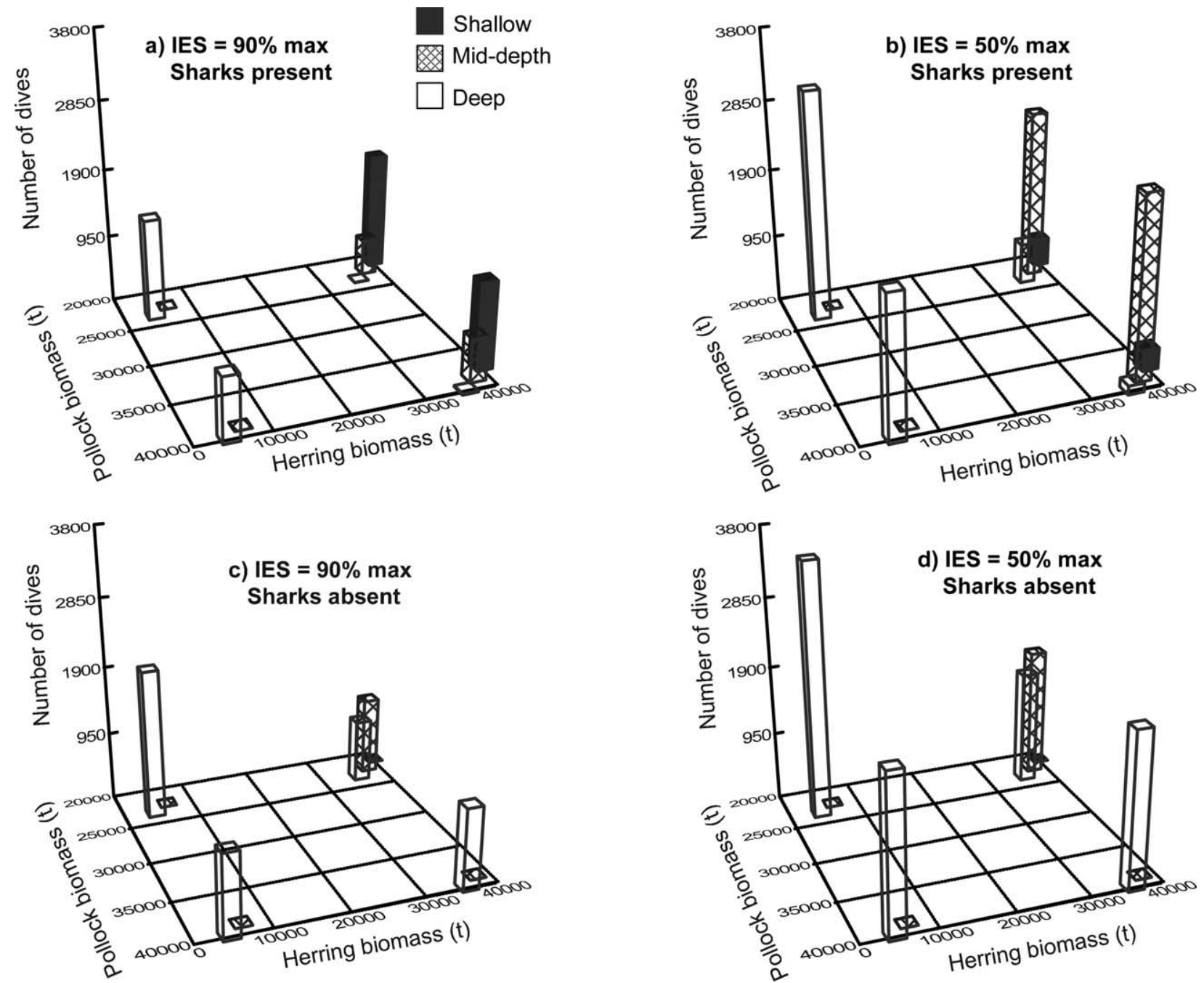

Fig. 1. Predicted number of dives by seals to each stratum, as influenced by their initial energy state (IES), herring and pollock abundance, and presence or absence of sleeper sharks. Values are the means of 1000 forward iterations (minus a few mortalities) covering the 23-d simulation period.

\section{Indirect effect of sharks on fish}

The indirect effect of sharks on pollock, as determined by Eq. 10, was substantial. Its strength, however, attenuated with herring scarcity and poor energy state (Fig. 2). Specifically, if initial energy state was good, the presence of sharks decreased pollock consumption by $70-81 \%$ if herring were abundant, but only $23-31 \%$ if herring were scarce(Fig. 2; values in range correspond to abundant and scarce pollock scenarios, respectively). If initial energy state was poor, the presence of sharks decreased pollock consumption by only $23-33 \%$ and $10-11 \%$ if herring were abundant and scarce, respectively (Fig. 2; values in each range correspond to scarce and abundant pollock scenarios, respectively).

The following results apply only to abundant herring scenarios; otherwise herring consumption was almost nil (Fig. 3). Regardless of initial energy state, herring consumption was greater in simulations that included shark risk. In the absence of sharks, herring consumption was substantial only if pollock were scarce (Fig. 3). (Under these conditions herring were consumed at mid-depth, rather than shallow strata: Fig. 1c-d). If pollock were scarce, the presence of sharks increased herring consumption 3.2-fold if initial energy state was high but only by $77 \%$ if initial energy state was low (Fig. 3).

Essentially, shark intimidation indirectly increased sealinflicted mortality of herring while decreasing seal-inflicted mortality of pollock. Poor initial energy state, however, attenuated these indirect effects (Fig. 4).

\section{Discussion}

Our model suggests that predation risk from sharks can produce an asymmetric trophic cascade mediated by the seal's underutilisation of deeper, riskier strata. During simulations, risk management by seals reduced mortality on pollock, which required riskier access in deep strata, while increasing mortality on herring, which could be accessed more safely in shallow strata. In shifting their foraging effort to herring, seals may pay the cost of reduced rates of net energy gain; although herring have higher energy density, their smaller size implies less energy gain per 

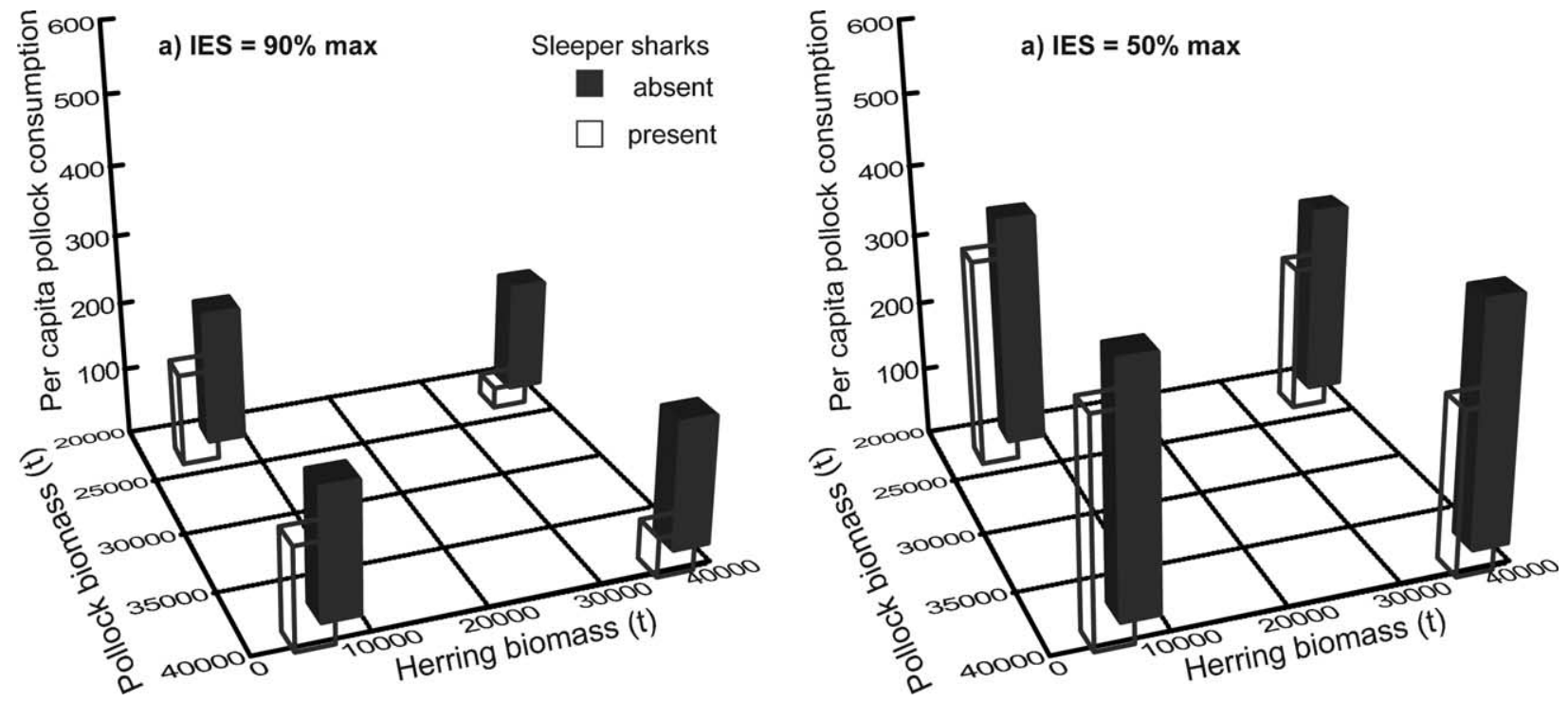

Fig. 2. Predicted pollock consumption by seals, as influenced by seal initial energy state (IES), herring and pollock abundance, and presence or absence of sleeper sharks. Values are the means of 1000 forward iterations (minus a few mortalities) covering the 23-d simulation period.

fish captured and their clumped distribution makes them the less predictable resource (Frid et al. 2007a).

Asymmetric trophic cascades mediated by the riskmanagement behaviour of mesoconsumers were first demonstrated experimentally by Schmitz (2003) in an old-field system and have been recently documented at the scale of entire landscapes (Fortin et al. 2005). Expanding on the insight of Schmitz (2003), our model predicts that the energy state of the mesoconsumer affects the level of asymmetry of top-down TMIIs. When herring were abundant and pollock scarce, shark risk caused a proportional increase to herring mortality that was four times greater if initial energy state was good than if it was poor, and a proportional reduction to pollock mortality that was
3.5 greater if initial energy state was good than if it was poor (Fig. 4). (Note, however, that when pollock were abundant shark removals released herring from seal predation completely, regardless of initial energy state: Fig. 3). Given that scarcity of one resource increased seal use of the alternative resource, in spite of the risks involved (Fig. 2 and 3), these dynamics partly arose from the lateral transmission of indirect effects initiated by alternative resources (Schmitz et al. 2004). Although limited evidence suggests that sharkinflicted mortality on Alaskan pinnipeds might not be substantial (Sigler et al. 2006), our results arise from the seal's 'fear' of sharks and need not invoke lethal interactions. As myriad studies indicate, predators can have strong nonlethal effects on their prey, even when direct mortality
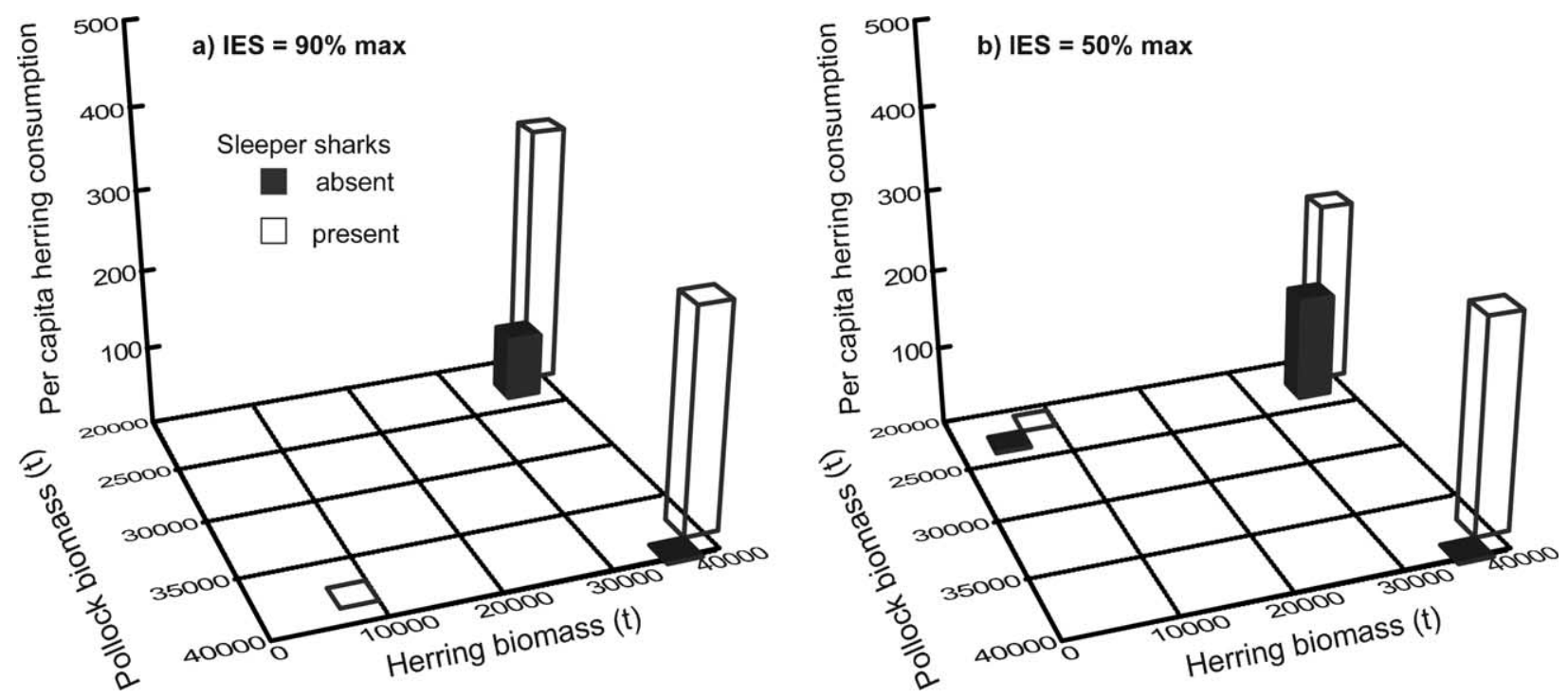

Fig. 3. Predicted herring consumption by seals during abundant herring scenarios and as influenced by initial energy state (IES) and the presence and absence of sharks. Values are the means of 1000 forward iterations (minus a few mortalities) covering the 23-d simulation period. 


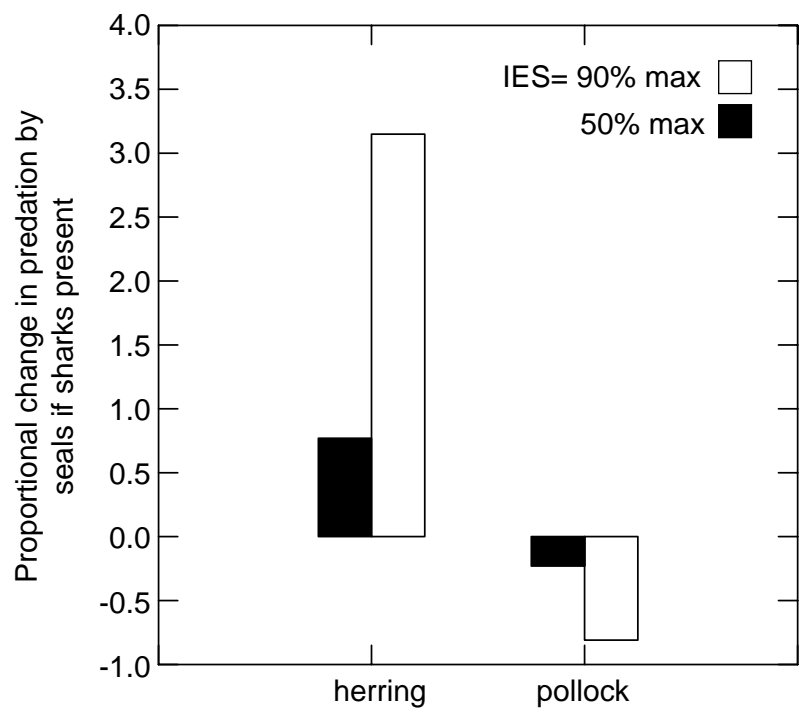

Fig. 4. Proportional difference in predation by seals on fish when sharks were present relative to when sharks were absent (Eq. 10), as influenced by initial energy state (IES). These results are limited to scenarios in which herring were abundant and pollock scarce (otherwise herring consumption was nil in the absence of sharks).

is rare (Lima and Dill 1990, Brown and Kotler 2004). Recent field studies demonstrate that systems involving sharks and marine mammals are no exception (Heithaus and Dill 2002, 2006, Wirsing et al. 2007a, 2007b).

Most notably, during simulations without shark risk seals increased their use of deep strata and their consumption of pollock, and stopped foraging on herring near the surface. These spatial shift and prey switching effectively reversed the asymmetric trophic cascade that previously had been driven by shark intimidation. Although resource levels and the energy state of individual mesoconsumers might modulate behavioural responses, the loss of shark intimidation could well be a substantial and under-appreciated mechanism via which shark fisheries can disrupt marine communities.

Our predictions are novel for three reasons. First, empirical studies on the nonlethal effects of sharks have quantified behavioural responses to shark intimidation by mesoconsumers (Heithaus and Dill 2002, 2006, Heithaus et al. 2007, Wirsing et al. 2007a, 2007b), yet stopped short of measuring indirect effects to lower trophic levels. Second, empirical studies specifically investigating how shark declines might affect community structure have focused on the density responses of mesopredators consumed by sharks (Shepherd and Myers 2005, Myers et al. 2007) without addressing nonlethal effects. Finally, Ecopath/Ecosim models evaluating the ecological impacts of shark declines (Kitchell et al. 2002) allow for activity reduction of mesopredators in response to predation risk (Walters et al. 2000), but do not allow for the spatial shifts and prey switching that reversed the asymmetric trophic cascade in our simulations. Although models have the advantage of including entire food webs, their coarser treatment of mesopredator behaviour could limit their applicability to some systems.

The effect of body condition or energy state - which is major feature of our model - may be critical for interpreting the ecological role of sharks. If poor energy state and resource levels synergistically limit the scope of antipredator behaviour (Anholt and Werner 1995, Luttbeg et al. 2003), then - according to our model - nonlethal effects of sharks and the ensuing behaviourally mediated trophic cascades should be substantial only when resources are abundant and the body condition of mesoconsumers is good.

Like all models, ours required a number of simplifications. As discussed earlier (see Model derivation), only two major resource species are considered, there is no density dependence and simulations represent a relatively short time span. Also, predators in our model were behaviourally inert, while in fact state-dependent responses of predator to prey and of prey to predator should be relevant (Alonzo et al. 2003). Still needed are demographic analyses using our model's output to parameterize life tables of fish and assess whether phenomena emerging from our simulations produce strong numerical responses. Our model, however, is the first application of state-dependent TMII theory to explore the ecological consequences of shark removals. Its predictions, therefore, have a heuristic value that is not undermined by our simplifications. Future models can build on this foundation.

Future work should also consider that both seals and sleeper sharks prey on walleye pollock (Iverson et al. 1997, Sigler et al. 2006), which raises questions about how intraguild predation might influence the system. A general model predicts that, when diet overlap is moderate or the intraguild predator is a poor competitor, intraguild prey should underutilise profitable but dangerous habitats while the intraguild predator should select habitats where the shared resource is more abundant (Heithaus 2001). While the relative competitive abilities of sleeper sharks and harbour seals are unknown, the overlap of pollock in their diets appears to be moderate; available data suggest that pollock are a major prey item for seals in our study area (Iverson et al. 1997) but have a lower relative importance in the diet of sleeper sharks (Sigler et al. 2006). Consistent with the prediction of Heithaus (2001), the foraging depths used by some individual seals generally under-match the availability of pollock at deep strata (Frid et al. 2007a), while sharks and pollock have more consistent spatial overlap (Frid et al. 2007a, Hulbert et al. 2006). Clearly, further work is needed on how dietary overlap could influence the equilibrium distributions of seals and sharks, and on the relative predation pressure that sharks and seals exert on pollock.

Unfortunately, we are unaware of empirical data on nonlethal interactions between sharks and pinnipeds that could test our predictions. Nonetheless, the following data-based arguments are consistent with the notion that nonlethal effects of sharks on mesopredators can indirectly affect lower trophic levels. First, the diving behaviour of airbreathing vertebrates that are potential prey of sharks, including several pinnipeds, often deviates from the time allocation (i.e. time at the surface, traveling through the water column, and foraging at a resource patch) that would, theoretically, maximise net energy gain. These deviations are qualitatively consistent with a model in which risk from submerged predators decreased the optimal time spent at an underwater foraging patch (Frid et al. 2007b), suggesting that pinnipeds might underutilise resources associated with higher risk from sharks. Second, in Shark Bay, Western Australia, where the density of tiger sharks varies seasonally, 
green turtles, dolphins, and dugongs underutilise profitable but dangerous microhabitats when shark density is high, yet increase use of these microhabitats when shark density decreases (Heithaus and Dill 2002, 2006, Heithaus et al. 2007, Wirsing et al. 2007a, 2007b). In the case of dugongs, excavation for the rhizomes of tropical seagrasses, which creates sediment plumes that limit visibility and antipredator vigilance, occurs only when shark density is relatively low; when shark density is higher, dugongs switch their foraging mode to cropping temperate seagrasses, which allows greater antipredator vigilance but also has the cost of lost foraging opportunities (Wirsing et al. 2007b). These observations are qualitatively consistent with the spatial and diet shifts that our model predicts should occur in response to the presence or absence of sharks. Third, the behaviour of green turtles in Shark Bay strongly supports our model's prediction that nonlethal effects of sharks are attenuated by poor energy state. During periods of high shark density, turtles in poor body condition made much greater use of dangerous habitats that did turtles in good condition (Heithaus et al. 2007).

While the Shark Bay studies are only suggestive of an indirect effect of sharks on lower trophic levels, behaviourally-mediated trophic cascades have been empirically quantified in systems involving mesoconsumers as diverse as ungulates under risk from wolves (Fortin et al. 2005), small mammals under risk from owls (Schmidt 2006), and marine invertebrate herbivores at risk from crabs and starfish (Byrnes et al. 2006), to mention but a few examples (reviewed by Werner and Peacor 2003 and Schmitz et al. 2004). There is no fundamental reason to expect systems where seals are under risk from sharks to be different.

Of course, empirical analyses are still required to validate our assumptions and predictions (see Frid 2007b for possible approaches). Yet even without conclusive empirical tests, our model is useful because it illustrates the theoretical plausibility that fishery removal of sharks can fundamentally alter predation pressure on different fish species via the state-dependent behavioural responses of mesoconsumers released from predator intimidation. These predictions are important because overfishing of sharks and other species are pressing global problems and rapid exploitation almost always outpaces empirical understanding of a system. Models like ours, therefore, are a form of imperfect advice to managers which - by uncovering potential scenarios that would not be elucidated explicitly without theory - can at least single out priorities for empirical research and feed the iterative process between empirical analyses, theory, and fisheries management (Hilborn and Mangel 1997). Given the paucity of data that characterises marine conservation efforts, such imperfect advice beats the alternative, which is no advice at all (Johannes 1998).

Acknowledgements - This paper is dedicated to Ransom Myers (Ram), an inspiring human being and powerhouse of marine science and conservation, who died an early death as this paper was being completed. Ram exemplified (in words borrowed from Michael Franti) 'a rebel who loves rocking to the beats'; his research inspired our paper. Research funds and/or financial support for AF were provided by the North Pacific Research Board, the Alaska Dept. of Fish and Game, the Prince William Sound Science Center, the Project Aware Foundation, and graduate scholarships from NSERC Canada and Simon Fraser Univ. NSERC Canada's grant A6869 supports LMD's research. We thank Bernie Roitberg, Marc Mangel, Mike Heithaus, Ron Ydenberg, Kenneth A. Schmidt and Gail Lotenberg for comments on earlier drafts, and Richard E. Thorne (Prince William Sound Science Center) for unpublished fish survey data.

\section{References}

Abrams, P. A. 1995. Implications of dynamically variable traits for identifying, classifying and measuring direct and indirect effects in ecological communities. - Am. Nat.146: 112-134.

Alonzo, S. H. et al. 2003. Ecological games in space and time: the distribution and abundance of Antarctic krill and penguins. - Ecology 84: 1598-1607.

Anholt, B. R. and Werner, E. E. 1995. Interactions between food availability and predation mortality mediated by adaptive behavior. - Ecology 76: 2230-2234.

Baum, J. K. et al. 2003. Collapse and conservation of shark populations in the northwest Atlantic. - Science 299: 389392.

Berger, J. et al. 2001. A mammalian predator-prey imbalance: grizzly bears and wolf extinction affect avian neotropical migrants. - Ecol. Appl. 11: 947-960.

Bowen, W. D. et al. 2001. Foraging effort, food intake, and lactation performance depend on maternal mass in a small phocid seal. - Funct. Ecol. 15: 325-332.

Brown, J. S. and Kotler, B. P. 2004. Hazardous duty pay and the foraging cost of predation. - Ecol. Lett. 7: 999-1014.

Byrnes, J. et al. 2006. Predator diversity strengthens trophic cascades in kelp forests by modifying herbivore behaviour. - Ecol. Lett. 9: 61-71.

Clark, C. W. 1994. Antipredator behavior and the asset-protection principle. - Behav. Ecol. 5: 159-170.

Clark, C. W. and Mangel, M. 2000. Dynamic state variable models in ecology. - Oxford Univ. Press.

Clarke, S. C. et al. 2006. Global estimates of shark catches using trade records from commercial markets. - Ecol. Lett. 9: 11151126.

Davis, R. W. et al. 1985. Swimming metabolism of yearling and adult harbor seals Phoca vitulina. - Physiol. Zool. 58: 590 596.

Fortin, D. et al. 2005. Wolves influence elk movements: behavior shapes a trophic cascade in Yellowstone National Park. - Ecology 86: 1320-1330.

Frid, A. et al. 2006. Do resource declines increase predation rates on North Pacific harbor seals? A behavior-based plausibility model. - Mar. Ecol. Prog. Ser. 312: 265-275.

Frid, A. et al. 2007a. Inferring prey perception of relative danger in large-scale marine systems. - Evol. Ecol. Res. 9: 635-649.

Frid, A. et al. 2007b. Dangerous dive cycles and the proverbial ostrich. - Oikos 116: 893-902.

Heithaus, M. R. 2001. Habitat selection by predators and prey in communities with asymmetrical intraguild predation. - Oikos 92: $542-554$.

Heithaus, M. R. and Dill, L. M. 2002. Food availability and predation risk influence bottlenose dolphin habitat use. - Ecology 83: 480-491.

Heithaus, M. R. and Frid, A. 2003. Optimal diving under the risk of predation. - J. Theor. Biol. 223: 79-92.

Heithaus, M. R. and Dill, L. M. 2006. Does tiger shark risk influence foraging habitat use by bottlenose dolphins at multiple spatial scales? - Oikos 114: 257-264.

Heithaus, M. R. et al. 2007. State-dependent risk-taking by green sea turtles mediates top-down effects of tiger shark intimidation in a marine ecosystem. - J. Anim. Ecol. 76: 837844. 
Hilborn, R. and Mangel, M. 1997. The ecological detective: confronting models with data. - Princeton Univ. Press.

Hulbert, L. et al. 2006. Depth and movement behaviour of the Pacific sleeper shark in the northeast Pacific Ocean. - J. Fish Biol. 69: 406-425.

Iverson, S. J. et al. 1997. Fatty acid signatures reveal fine scale structure of foraging distribution of harbor seals and their prey in Prince William Sound, Alaska. - Mar. Ecol. Prog. Ser. 151: 255-271.

Johannes, R. E. 1998. The case for data-less marine resource management: examples from tropical nearshore finfisheries. - Trends Ecol. Evol. 13: 243-246.

Johnson, C. et al. 2007. Rarity of a top predator triggers continent-wide collapse of mammal prey: dingoes and marsupials in Australia. - Proc. R. Soc. Lond. B 274: 341346.

Kitchell, J. F. et al. 2002. The role of sharks and longline fisheries in a pelagic ecosystem of the central Pacific. - Ecosystems 5: 202-216.

Kramer, D. L. 1988. The behavioral ecology of air breathing by aquatic animals. - Can. J. Zool. 66: 89-94.

Lima, S. L. and Dill, L. M. 1990. Behavioural decisions made under the risk of predation. - Can. J. Zool. 68: 619-640.

Luttbeg, B. et al. 2003. Prey state and experimental design affect relative size of trait- and density-mediated indirect effects. - Ecology 84: 1140-1150.

Matkin, C. O. et al. 2003. Photographic and acoustic monitoring of killer whales in Prince William Sound and Kenai Fjords - Exxon Valdez Oil Spill Restoration Project 030012 Final Rep.

McNamara, J. M. and Houston, A. I. 1987. Starvation and predation as factors limiting population size. - Ecology 68: 1515-1519.

Mitchell, W. A. and Lima, S. L. 2002. Predator-prey shell games: large-scale movement and its implications for decision-making by prey. - Oikos 99: 249-259.

Myers, R. A. et al. 2007. Cascading effects of the loss of apex predatory sharks from a coastal ocean. - Science 315: 18461850.

Paul, A. J. et al. 1998. Fall and spring somatic energy content for Alaskan Pacific herring (Clupea pallasi Valenciennes 1847) relative to age, size and sex. - J. Exp. Mar. Biol. Ecol. 223: 133-142.

Rosen, D. A. S. et al. 2000. Effect of ration size and meal frequency on assimilation and digestive efficiency in yearling Steller sea lions, Eumetopias jubatus. - Aquat. Mamm. 26.1: 76-82.

Saulitis, E. et al. 2000. Foraging strategies of sympatric killer whale (Orcinus orca) populations in Prince William Sound, Alaska. - Mar. Mamm. Sci. 16: 94-109.

Scheffer, M. et al. 2005. Cascading effects of overfishing marine systems. - Trends Ecol. Evol. 20: 579-581.

Schmidt, K. 2006. Non-additivity among multiple cues of predation risk: a behaviorally-driven trophic cascade between owls and songbirds. - Oikos 113: 82-90.

Schmitz, O. 2003. Top predator control of plant biodiversity and productivity in an old-field ecosystem. - Ecol. Lett. 6: 156163.

Schmitz, O. J. et al. 2004. Trophic cascades: the primacy of traitmediated indirect interactions. - Ecol. Lett. 7: 153-163.

Shepherd, T. and Myers, R. A. 2005. Direct and indirect fishery effects on small coastal elasmobranchs in the northern Gulf of Mexico. - Ecol. Lett. 8: 1095-1104.

Sigler, M. F. et al. 2006. Diet of Pacific sleeper shark, a potential Steller sea lion predator, in the northeast Pacific Ocean. - J. Fish Biol. 69: 392-405.
Sinclair, A. R. E. and Arcese, P. 1995. Population consequences of predation-sensitive foraging: the Serengeti wildebeest. - Ecology 76: 882-891.

Thomas, G. L. and Thorne, R. E. 2001. Night -time predation by Steller sea lions. - Nature 411: 1013.

Thomas, G. L. and Thorne, R. E. 2003. Acoustical-optical assessment of Pacific herring and their predator assemblage in Prince William Sound, Alaska. - Aquat. Living Resour. 6: 247-253.

Thorne, R. E. 2004. Biological monitoring of herring and pollock in Prince William Sound. - Annu. Prog. Rep. Oil Spill Recovery Inst., Contract no. 03-10-23, Prince William Sound Science Center.

Trumble, S. J. et al. 2003. Digestive constraints on an aquatic carnivore: effects of feeding frequency and prey consumption on harbor seals. - J. Comp. Physiol. B 173: 501-509.

Vollenweider, J. J. 2004. Variability in Steller sea lion (Eumetopias jubatus) prey quality in southeastern Alaska. - Univ. of Alaska, Fairbanks.

Walters, C. J. et al. 2000. Representing density dependent consequences of life history strategies in aquatic ecosystems: ECOSIM II. - Ecosystems 3: 70-83.

Werner, E. E. and Peacor, S. D. 2003. A review of trait-mediated indirect interactions in ecological communities. - Ecology 84: 1083-1100.

Williams, T. M. et al. 2000. Sink or swim: strategies for costefficient diving by marine mammals. - Science 288: 133-136.

Wirsing, A. J. et al. 2007a. Living on the edge: dugongs prefer to forage in microhabitats that allow escape from rather than avoidance of predators. - Anim. Behav. 74: 93-101.

Wirsing, A. J. et al. 2007b. Can you dig it? Use of excavation, a risky foraging tactic, by dugongs is sensitive to predation danger. - Anim. Behav. In press.

\section{Appendix 1. Sensitivity analyses of the terminal fitness function.}

The terminal fitness function had a power shape and exponent 3.25 (Eq. 1). Here we explore how predicted depth choice, the main mechanism for transmission of indirect effects, responds to the exponent's value while other parameters are held at baseline values (Table 1,2).

As Fig. A1 illustrates, predictions changed with \pm 0.25 differences in the exponent's value, particularly at the extremes of the range of values explored and if initial energy state was poor. So which is the 'best' exponent? Or for that matter - is an alternative functional shape more appropriate? The first question might be answered by an adequate data set for empirically testing behavioural predictions - something we lack. The second might be answered by year-round monitoring of seal behaviour and body condition, followed by analyses of how these factors influence reproductive success (see Bowen et al. 2001 for an example). Meanwhile - given that predicted changes were moderate when changing the original exponent by \pm 0.25 (Fig. A1) - the function we used arguably is a reasonable starting point for future research.

We also note that predictions are sensitive to the level of herring abundance. When using baseline resource encounter probabilities (Table 2), almost no shallow dives occurred, regardless of the exponent's value in the terminal fitness function (Fig. A1). A substantial number of shallow dives occurred only during simulations in which herring abundance (and hence the probability of seals encountering 


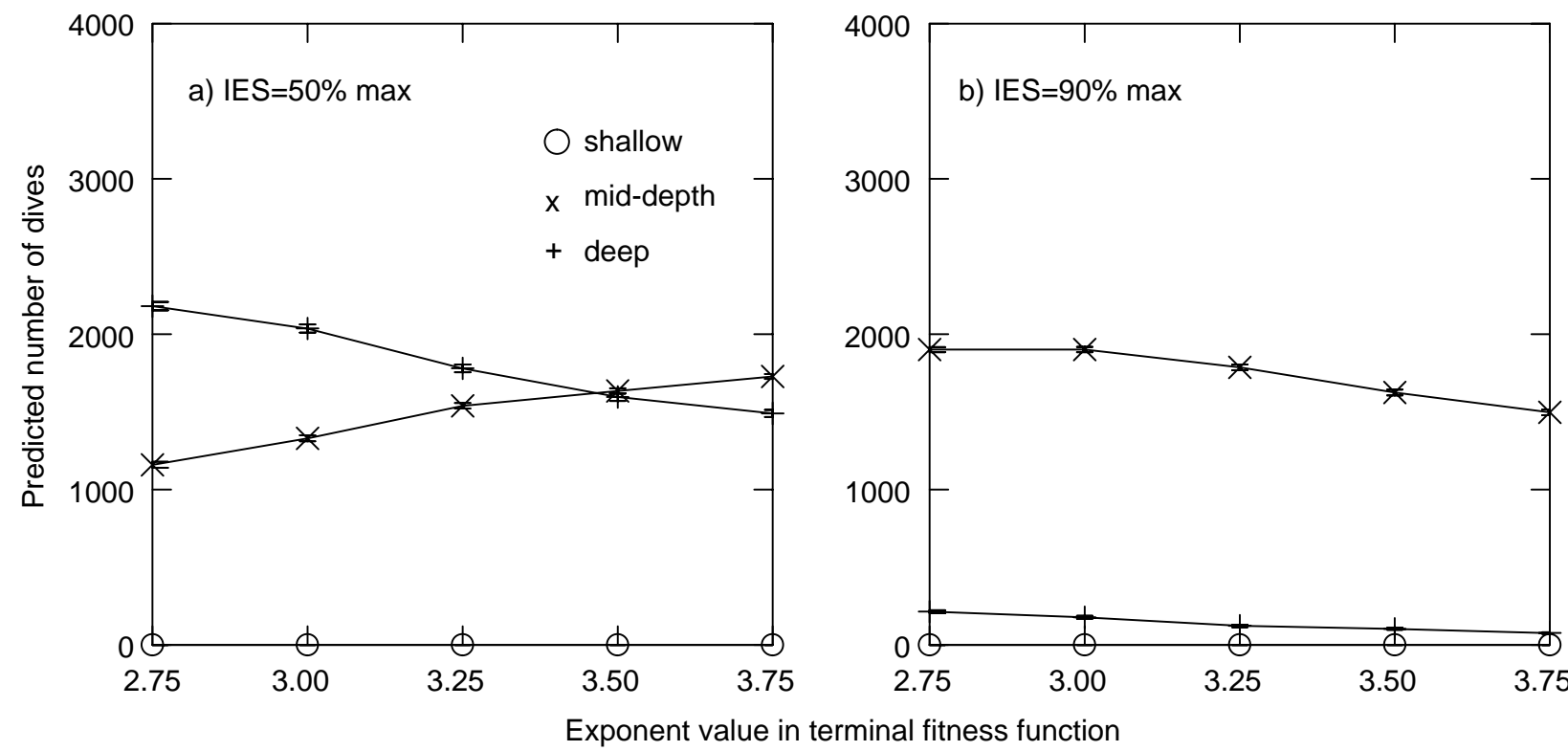

Fig. A1. Predicted depth choice by seals as influenced by initial energy state (IES) and the value of the exponent in the terminal fitness function (Eq. 1). All other parameter values were held constant at baseline values (Table 1 and 2 ). Results are the means ( \pm SE, which are small and barely visible) of 1000 forward simulations per treatment; but simulations in which predation occurred are excluded.

herring) was greater than baseline levels (Fig. 1a-b). Our computer experiments therefore might represent only a partial range of conditions under which seals select shallow strata. Accordingly, we emphasise that the heuristic value of our model is in predicting qualitative (i.e. directional) changes to use of different strata in response to synergistic effects of resources and predators. Clark and Mangel (2000) offer a general discussion on these issues.

\section{Appendix 2. Further information on parameterisation}

Figure A2 is a partial reprinting of Fig. 1 of Frid et al. (2007a); it summarises essential features of that paper used to parameterise the current model. Panels (a) and (b) show, by diel period, the empirically-based estimates of the proportions of time each predator type spent at different depths (i.e. values for $T_{i, s, \delta}$ in Eq. 9). Panel (a) is based on unpublished data for 10 mammal-eating killer whales in southeast Alaska (P.J.O. Miller, A.D. Shapiro and V.B. Deecke unpubl.). Panel (b) is based on the subset of sharks studied by Hulbert et al. (2006) for which depths were recorded every min (see their Methods). While the small sample size of sharks is not ideal, these sharks' pattern of depth use within the strata used by seals $(0-300 \mathrm{~m})$ was qualitatively similar to that of eight other sharks for which coarser behavioral data were available. Namely, all 11 sharks spent more time at depths of $100-300 \mathrm{~m}$ than in shallower strata and, with one exception, rarely used depths shallower than $50 \mathrm{~m}$ (Table V of Hulbert et al. 2006). Panel (c) shows resource encounter probabilities in relation to depth and diel period (i.e. the values for $P_{s, \delta}$ in Eq. 8); they were derived by combining empirical data on fish distributions with theoretical calculations (Appendix A and Eq. 1 of Frid et al. 2007a).
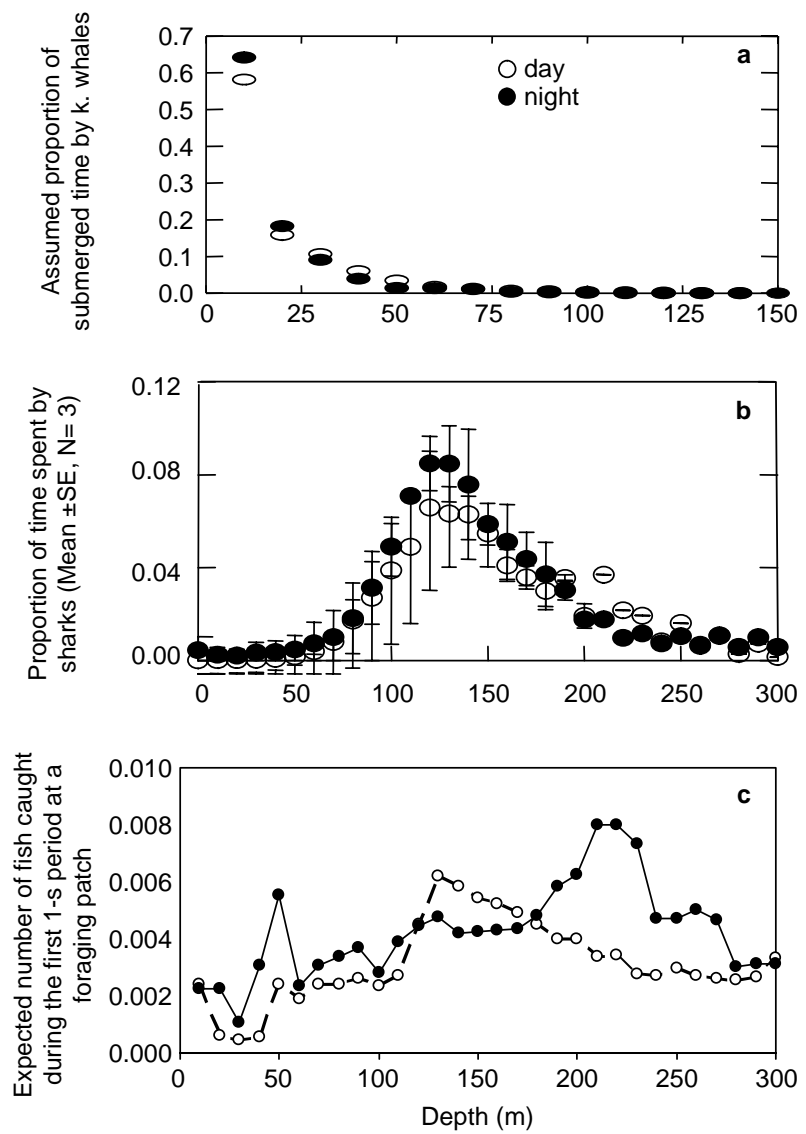

Fig. A2. (reprinted in part from Frid et al. 2007a) 